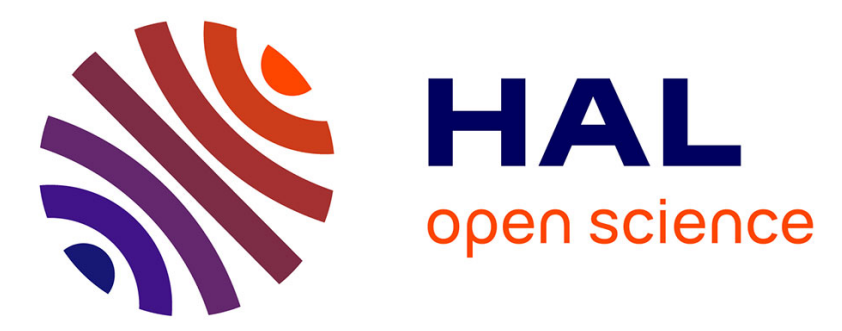

\title{
AN ATOM-PROBE STUDY OF COMPOSITIONAL VARIATIONS IN THE NEAR-SURFACE LAYERS OF BINARY ALLOYS
}

Mumtaz Ahmad, T. Tsong

\section{- To cite this version:}

Mumtaz Ahmad, T. Tsong. AN ATOM-PROBE STUDY OF COMPOSITIONAL VARIATIONS IN THE NEAR-SURFACE LAYERS OF BINARY ALLOYS. Journal de Physique Colloques, 1986, 47 (C2), pp.C2-375-C2-379. 10.1051/jphyscol:1986258 . jpa-00225692

\section{HAL Id: jpa-00225692 https://hal.science/jpa-00225692}

Submitted on 1 Jan 1986

HAL is a multi-disciplinary open access archive for the deposit and dissemination of scientific research documents, whether they are published or not. The documents may come from teaching and research institutions in France or abroad, or from public or private research centers.
L'archive ouverte pluridisciplinaire HAL, est destinée au dépôt et à la diffusion de documents scientifiques de niveau recherche, publiés ou non, émanant des établissements d'enseignement et de recherche français ou étrangers, des laboratoires publics ou privés. 


\title{
AN ATOM-PROBE STUDY OF COMPOSITIONAL VARIATIONS IN THE NEAR-SURFACE LAYERS OF BINARY ALLOYS
}

\author{
M. AHMAD and T.T. TSONG \\ The Pennsylvania state University, Physics Department, University \\ Park, Pa 16802, U.S.A.
}

\begin{abstract}
Quantitatively reliable equilibrium composition depth profiles with true single atomic layer depth resolution have been obtained for the (001) plane of a Pt-Ir and five Pt-Rh alloys. Pt segregates to the top two layers in Pt-Ir alloy. Pt concentration decreases monotonically towards the bulk value. Rh segregates to the top layer in Pt-Rh alloys and the concentration profile is oscillatory. In addition, cosegregation of impurity sulfur (Iess than $100 \mathrm{ppm}$ in the bulk) and formation of a chemisorbed overlayer has been observed.
\end{abstract}

\section{INTRODUCTION}

In thermodynamic equilibrium the surface composition of an alloy may be different from that in the bulk due to segregation of one of the species. Surface segregation has great implication in alloy catalysis, 1 physical metallurgy and materials properties. 2 Although several sophisticated surface analytical tools are being used to study surface segregation, accurate equilibrium in-depth composition profiles with true single atomic layer depth resolution have been obtained only by the time-of-flight atomprobe. This.work is directed towards obtaining detailed information on the compositional variations in the near-surface layers in binary $\mathrm{Pt-based} \mathrm{alloys} \mathrm{which} \mathrm{are}$ important in catalysis. 3 Along with the segregation of alloy constituents, a minute amount of impurity sulfur in the bulk has been found to cosegregate and form an overlayer on the surface. Sulfur has a strong poisoning effect in many catalytic reactions, 4 therefore a study of the surface segregation of sulfur is important.

Experimental procedure for obtaining surface segregation results using an atom-probe has been outlined in previous reports.5-8 In the present case the inclusion of the impurity overlayer will be briefly described. The background vacuum has always been maintained at $2 \times 10^{-10}$ Torr or better, while residual gas analyzer shows no trace of oxygen. The necessary pre-treatment to clean the samples is carried out and the bulk composition of each alloy has been determined from at least several thousand ions. The high voltage pulse fraction and the pulse per detected particles have been carefully selected to avoid preferential field evaporation of one species. The impurity level is found to be less than $100 \mathrm{ppm}$.

Once a well-developed surface has been obtained, the sample is annealed in field free condition at $700^{\circ} \mathrm{C}$ for 5 minutes and then quenched to 1iquid nitrogen temperature to freeze the thermal redistribution of the alloying species. The image of the thermal endform always shows large facetting on the (001) plane. It has been observed earlier that sometimes an FI image of a thermal endform for an alloy shows extremely dim image of the top layer due to strong segregation of one species, namely in $\mathrm{Ni}-\mathrm{Cu} .5$ For all the alloys studied in the present case a somewhat different result has been observed. 
As the dc field is gradually raised (still well below the evaporation field) the FI image of the endform shows several spots close to the edge of the top layer. On further raising the fleld these spots become brighter and form the edge of an overlayer. These atoms are found to be more resistive to field evaporation and they evaporate together with the edge atoms of the substrate layer. Due to the problem of field evaporating the overlayer smoothly or resolving the edges of the overlayer and the first layer, these two edges are aimed together at the probe hole for surface segregation studies. The usual slow pulse field evaporation with the probe hole aimed at at the edge(s) of the top layer is continued and the evaporated ions are sequentially recorded. Each layer is studied separately as controlled by visual monitoring. There is no intermixing of signals from adjacent atomic layers and thus the depth profiles have single atomic layer spatial depth resolution. Although intermixing of signals from the overlayer and the first layer has occurred, it does not affect the depth resolution since, in this case the top layer concentration is easily derived by subtracting the contribution from the overlayer. With the procedure followed it is possible to determine the overlayer coverage. For statistical reliability the experiment is repeated several times for several tips under identical heat treatment, and the cumulative number of ions collected from each layer ranges from several hundreds to over a thousand ions.

Most of the ions detected from the overlayer has a mass-to-charge ratio of 16 amu. A plot of the combined histogram of the mass signals from the overlayers indicate that

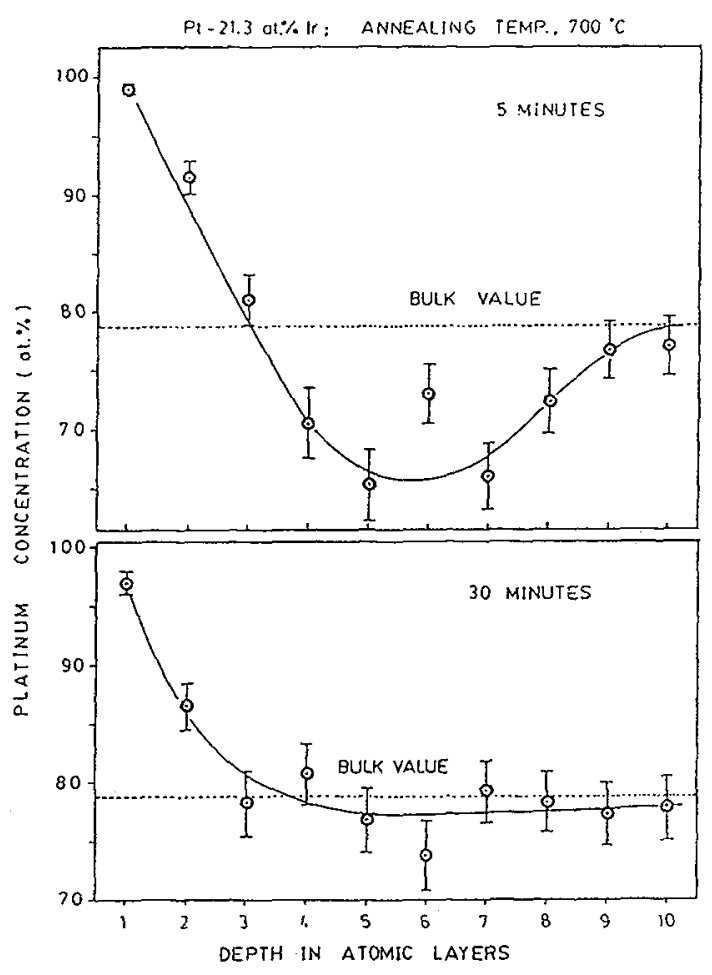

FIG. 1. Composition depth profiles of the (001) plane of a Pt-21.3 at.\% Ir alloy with 5 and 30 minutes annealing at $700^{\circ} \mathrm{C}$.

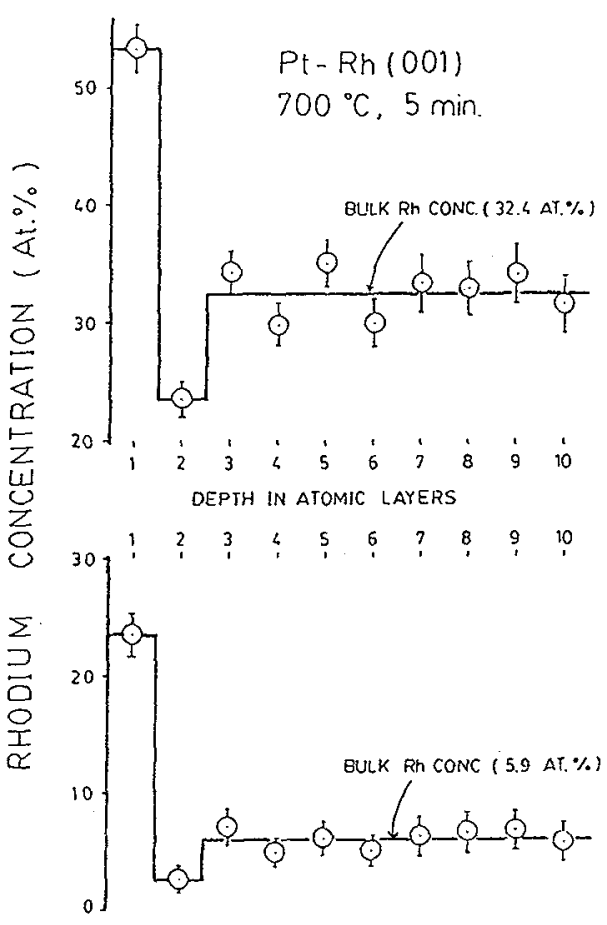

FIG. 2. Composition depth profiles of a Pt-32.4 at.\% $\mathrm{Rh}$ and $\mathrm{Pt}-5.9$ at.\% $\mathrm{Rh}$ alloy (001) plane obtained after annealing the samples at $700^{\circ} \mathrm{C}$ for 5 minutes. 
these are sulfur mass peaks. In addition an excellent agreement has been found between the experimentally determined isotopic abundances of sulfur atoms and the standard table values confirming that these are indeed atoms cosegregated from the bulk.

Two concentration depth profiles (CDPs) at $700^{\circ} \mathrm{C}$, one after 5 minutes annealing and one after 30 minutes annealing for the (001) plane of a Pt-21.3at\% Ir alloy are shown in Fig. 1. Though both the profiles show similar Pt enrichment in the top two layers, the 5 minute data shows a significant Ir enrichment from the 4 th to the 8th atomic layer. For slowly diffusing species an incomplete thermodynamic equilibrium gives rise to metastable profiles such as this which can be removed by annealing for a period of time or by annealing at a higher temperature. Throughout the course of this study careful test has been made to establish the right conditions for real global thermodynamic equilibrium.

Figure 2 shows two CDPs for the (001) plane of two different Pt-Rh alloys annealed at $700^{\circ} \mathrm{C}$ for 5 minutes. Both these show Rh segregation to the first layer with a significant $R h$ depletion in the second layer. The alloy composition returns to the bulk value from the third layer on. Three other alloys with different Rh concentrations have been studied and they all show similar behavior, as shown in Fig. 3 . The question regarding equilibrium nature of these alloys has been resolved by annealing one sample at $800^{\circ} \mathrm{C}$ and similar depth profile has been obtained. The sequential detection

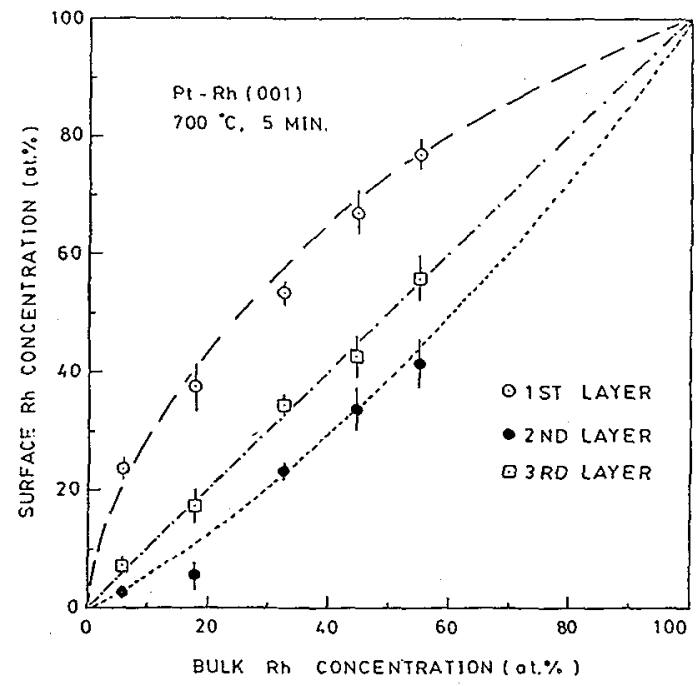

FIG. 3. Compositions of the top three (001) layers in five $\mathrm{Pt}-\mathrm{Rh}$ alloys studied.

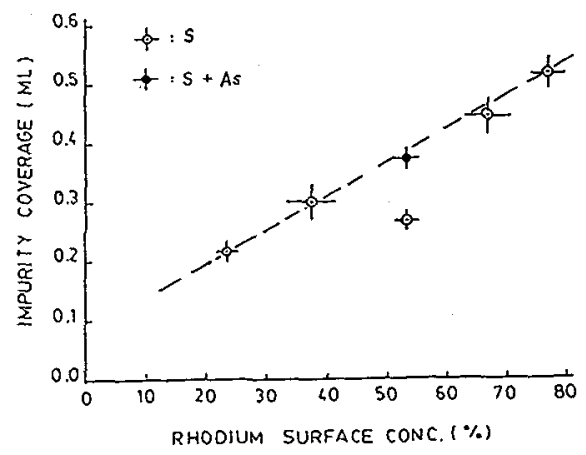

FIG. 4. A plot of the dependence of impurity coverage on surface $R h$ concentration for Pt-Rh (001) plane at $700^{\circ} \mathrm{C}$. Open circles represent sulfur coverage only, and the closed circle represents the combined sulfur and arsenic coverage; a small amount of As has been detected in one of the alloys.

process, given as the lateral concentration profile (LCP), shows a uniform Rh concentration in the lateral direction from the plane edge to the center. Although in the case of the stepped surface at edge of the first layer an edge effect is expected, i.e., increasing enrichment of the segregant, we have not observed this effect perhaps due to the overlap of the first layer and the overlayer. Similar LCPs for $S$ shows a fairly uniform sulfur coverage on the first layer. Sulfur concentration beneath the first layer is practically zero, only occasionally one or two $S$ atoms have been found on the second layer. The Rh surface concentration and the corresponding $S$ coverage for all the Pt-Rh alloys are plotted in Figure 4 . It shows that $S$ coverage ranges between 0.22 to 0.52 monolayer and increases with increasing $\mathrm{Rh}$ concentration on the surface. This indicates that $\mathrm{Rh}-\mathrm{S}$ chemisorption bond forma- 
tion may be energetically more favorable than the Pt-S bond. For the Pt-Ir (001) plane, approximately 0.18 monolayer of $\mathrm{S}$ has been detected. Although in principle one can study the formation of these bonds by treating the field evaporation events as a Markov chain, 9 we are not able to do it here since, the sulfur atoms are not in the same layer as the metal atoms. Their field evaporation behavior is not we1lunderstood either.

overlayer superstructure formation in some systems, notably Si on W, using FIM has been reported earlier by Tsong and Casanova, 10 in the present case $15 \mathrm{~K}$ image of the thermal endform does not show any ordered superstructure. In some instances overlayer images have shown resemblance to square $c(2 \times 2)$ structure. The detailed imaging property of adsorbed sulfur atoms on these alloy surfaces needs to be understood before a true evaluation of such structure is made. Even though adsorbed sulfur superstructure on Pt surfaces is well-established from LEED studies, 11 it may not be appropriate to predict the same ordering for the alloy surface, especially when there is an indication of stronger chemisorption bond between $R$ h and $S$ atoms. This is an interesting problem worth further investigation.

Segregation of Pt in Pt-Ir alloy is consistent with all the existing models. The interesting feature is the monotonic decrease of $\mathrm{Pt}$ concentration towards the bulk value instead of an abrupt change. Such a feature has been previously observed for Pt-Au alloys where Au segregates to the top four layers. 6 Segregation of Rh to the surface of $\mathrm{Pt}-\mathrm{Rh}$ alloy is consistent with the bond-breaking model since Rh has the lower heat of sublimation. According to the atomic model proposed by Abraham et al., 12 Rh will segregate while a later modification of the model by Abraham 13 predicts Pt segregation. The surface energy model of Hamilton 14 and the simplified electronic model of Lambin et al.15 predict Pt segregation. Experimentally, William and Nelson reported observation of $\mathrm{Pt}$ segregation in Pt-Rh alloys in an ion scattering experiment. 16 However no details of their experimental condition such as vacuum and impurity content and details of results were given in the paper which is a summary abstract. The disagreement between various models in surface segregation is not uncommon. It is difficult to say with any certainty which model is correct for this system due to the presence of an adsorbed sulfur layer. Our observation of Rh enrichment nay also indicate the influence of chemisorption in changing surface composition. Obviously for our next study, PtRh alloys of ultra-high purity should be used. Unfortunately, such alloys are almost impossible to acquire. Sulfur segregation is of course a subject of great importance since $S$ affects the reactivity of a surface in a dramatic way.

The most interesting finding of this system is the depletion of Rh in the second layer. Such nonmonotonic profiles have been treated so far only by quasichemical models in which surface bond relaxation is estimated in an ad-hoc way to obtain an oscillatory depth profile.17,18 A recent pseudopotential calculation by Barnett et al. shows that a single ion potential at simple metal surface oscillates around a bulk value and decays within a few atomic layers into the bulk.18 It is this oscillation that determines equilibrium surface structure and surface relaxation. It may be possible that the single ion potential is also responsible for the oscillatory composition profiles, since the segregating elements should redistribute under the influence of such a potential.

Table I. Binary Alloy Surface Segregation Behavior Observed in Atom-probe Studies.

\begin{tabular}{lcccc}
\hline & $\begin{array}{c}\text { Extent of } \\
\text { Segregation } \\
\text { Alloy System }\end{array}$ & $\begin{array}{c}\text { Segregating } \\
\text { Element } \\
\text { of Atomic } \\
\text { Layers) }\end{array}$ & $\begin{array}{c}\text { Nature of } \\
\text { Covergence } \\
\text { to Bulk Value }\end{array}$ & Reference \\
\hline $\mathrm{Pt}-\mathrm{Rh}$ & $\mathrm{Rh}$ & 1 & Oscillatory & 8 \\
$\mathrm{Pt}-\mathrm{Ir}$ & $\mathrm{Pt}$ & 2 & Monotonic & 7 \\
$\mathrm{Pt}-\mathrm{Au}$ & $\mathrm{Au}$ & 4 & Monotonic & 6 \\
$\mathrm{Ni}-\mathrm{Cu}$ & $\mathrm{Cu}$ & 1 & Oscillatory & 5 \\
\hline
\end{tabular}


The recent results obtained by the atom-probe is listed in Table I. It is found that the compositional variation in the near-surface region can be both monotonic and nonmonotonic in nature. As the atom probe can provide accurate information on the compositional variation in the near-surface layers of alloys with single atomic layer resolution, these data should be useful to both theorists and experimentalists. The variety of the depth profiles should shed some light on the atomic interactions in the surface region. Surface relaxation and reconstruction processes are of considerable importance and the depth profiles strongly indicate one or both of these processes may be responsible for giving rise to different compositional variations in the near surface layers we have observed.

\section{ACKNOWLEDGMENTS}

The work was supported by the NSF under grant number DMR-8217119. The authors acknowledge the valuable technical assistance of Mr. S. B. McLane, Jr.

\section{REFERENCES}

/1/ V. Ponce, Surf. Sci., 80, (1979) 352.

$/ 2 /$ D. Mclean in Grain Boundaries in Metals," Oxford (1957).

/3/ J. C. Rasser in "Platinum Iridium Reforming Catalysts," Delft University Press, Delft, The Netherlands (1977).

/4/ J. Oudar, Catal. Rev. Sci. Engg. 22, (1980) 171.

$/ 5 /$ Y. S. Ng, T. T. Tsong and S. B. McLane, Phys. Rev. Lett 42, (19.79) 588.

/6/ T. T. Tsong, Y. S. II and S. B. McLane, J. Chem. Phys. 73, (1980) 1464.

/7/ M. Ahmad and T. T. Tsong, Appl. Phys. Lett. 44 , (1984) $\overline{40}$.

$18 / \mathrm{M}$. Ahmad and T. T. Tsong, Surf. Sci. 149, (1985) L7; also J. Chen. Phys. July (1985).

/9/ T. T. Tsong, S. B. McLane, M. Ahmad and C. S. Wu, J. App1. Phys. 53, (1982) 4180. $/ 10 /$ T. T. Tsong and R. Casanova, Phys. Rev. Lett. 47, (1981) 113.

/11/ W. Heegeman, K. H. Meister, E. Bechtold and K. Hayek, Surf. Sci, 49, (1975) 161.

$/ 12 /$ F. F. Abraham, N. - H Tsai and G. M. Pound, Surf. Sci. 83, (1979) $4 \overrightarrow{06}$.

/13/ F. F. Abraham, Phys. Rev, Lett. 46, (1981) 546.

/14/ J. C. Hamilton, Phys. Rev. Lett. $\overrightarrow{42}$, (1979) 989.

/15/ Ph. Lambin and J. P. Gaspard, J. Phys. F 10, (1980) 2413.

$/ 16 /$ F. L. Williams and G. C. Nelson, J. Vac. Sci. Technol. 16, (1979) 663.

$/ 17 /$ Y. S. Ng, T. T. Tsong and S. B. McLane, Surf. Sci. 84, (1979) 31.

/18/ V. Kumar, Phys. Rev. B23, (1981) 3756.

/19/ R. N. Barnett, R. G. Barrera, C. L. Cleveland and U. Landman, Phys. Rev. B29,

(1983) 1667 . 